\title{
Controversial effects of fumed silica on the curing and thermomechanical properties of epoxy composites
}

\author{
J. Tarrío-Saavedra1, J. López-Beceiro ${ }^{2}$, S. Naya ${ }^{2}$, C. Gracia ${ }^{3}$, R. Artiaga ${ }^{2}$ \\ ${ }^{1}$ Department of Mathematics, EPS. University of A Coruna. Avda. Mendizábal s/n. 15403. Ferrol, Spain \\ ${ }^{2}$ Department of Industrial Engineering II, EPS. University of A Coruna. Avda. Mendizábal s/n. 15403. Ferrol, Spain \\ ${ }^{3}$ Thermal Analysis, Rheology and Microcalorimetry Applications. TA Instruments - Waters Cromatografía, S.A. Avda. \\ Europa, 21 Parque Empresarial La Moraleja 28108. Alcobendas Madrid, Spain
}

Received 10 February 2010; accepted in revised form 24 April 2010

\begin{abstract}
The effect of fumed silica on the curing of a trimethylolpropane epoxy resin was investigated by thermal analysis methods like Differential Scanning Calorimetry (DSC), and Dynamic Mechanical Analysis (DMA). The fumed silica used here is a by-product of the silicon and ferrosilicon industry, consisting of micro and nanosized particles. Both the curing reaction and the properties of the obtained composites were affected by the filler content. Different trends were observed for filler contents above and below the $30 \mathrm{wt} \%$. Up to $30 \mathrm{wt} \%$, the behaviour can be explained as a predominantly agglomeration effect. For $30 \mathrm{wt} \%$ and higher filler contents, single particles seem to play a more important role.
\end{abstract}

Keywords: polymer composites, thermal properties, thermosetting resins, fumed silica, viscoelastic properties

\section{Introduction}

Although epoxy resins are widely used, their application is somewhat limited due to their brittleness derived from a highly cross-linked structure. The mechanical properties of epoxy resins can, however, be improved by incorporating inorganic particles [1]. It is well known that particle volume, shape, size, surface characteristics and particle dispersion within the matrix have an influence on the mechanical properties of the composites [2-5]. Specific surface area can promote stress transfer from matrix to nanoparticles and improve the Young's modulus of polymers to a higher extent than micro-fillers. Consequently, the required nanoparticle contents in polymer matrices are usually much lower as compared to micro-fillers [6]. The formation of organic-inorganic nanocomposites has shown the ability to provide simultaneous improvements in several properties including thermal sta- bility, glass transition temperature levelling, dimensional stability, flame retardance, dielectric constant lowering and gas barrier and corrosion protection [6-15]. The degree of interaction between filler and polymer and thus the composite properties have been related to the filler-matrix interface. As defined in traditional composites, by Drzal et al. [16], and Schadler [17], the interfacial region is the region beginning at the point in the fiber at which the properties differ from those of the bulk filler and ending at the point in the matrix at which the properties become equal to those of the bulk matrix. The chemistry, polymer chain mobility, degree of cure, and crystallinity are likely to be altered in that region. Its thickness has been reported to be in the 2 to $50 \mathrm{~nm}$ range [17]. The interphase can have a significant effect, both positive and negative, on the mechanical properties of the composite: when the glass transition tempera- 
ture, $T_{g}$, of the interphase is less than that of the matrix, the $T_{g}$ of the composite decreases with filler addition. But, if the $T_{g}$ of the interface is higher than that of the matrix, the $T_{g}$ of composite will increase by increasing filler content [18]. Synergistic effects were found in the form of a further increase in wear resistance, stiffness, fracture toughness and tensile and impact strengths by mixing nano and microparticles [19-21]. Processing methods producing controlled particle size distribution, dispersion, and interfacial interactions would be advisable to obtain customized properties in new composites. Thus, the dispersion of nanoparticles in a polymer matrix has a significant impact on the properties of nanocomposites. Methods to improve the dispersion of nanoparticles into the matrix include, but are not limited to, mechanical mixing and ultrasonic dispersion $[8$, 10], surface modification of nanoparticles [10, 22, 23] and sol-gel process [24, 25].

On other hand, thermal analysis techniques are usually employed in the study of thermal stability, curing reactions, glass transition and thermomechanical properties. Thermal stability of polymers and composites is usually evaluated by thermo-gravimetric analysis (TG) [10, 26]. Differential scanning calorimetry (DSC) has been used to study the degree of curing of thermosets by calculating the heat of cure from the area enclosed in the exothermal peak $[10,18,27]$. In non-homogeneous materials, like composites, the reaction heat should be divided by the mass of resin. Sealed crucibles are recommended in order to prevent volatilization, which would appreciably affect the measured heat [18]. The experiments should start at temperatures low enough in order to prevent any curing reaction from taking place before the data acquisition starts. In standard DSC, a heating rate of $10^{\circ} \mathrm{C} \mathrm{min}^{-1}$ is usually recommended to promote an adequate balance between resolution and sensitivity [18]. Thermal glass transition refers to the immobilization or freezing-in at the transition from the liquid to the glassy state in cooling experiments [28]. The glass transition temperature is usually defined on cooling from the equilibrium liquid to the glassy state, and is a function of cooling rate [29]. Therefore the $T_{g}$ is usually measured by standard DSC at $10^{\circ} \mathrm{C} \mathrm{min}-1$ cooling rate. Modulated temperature DSC (MTDSC) is a refinement of the standard DSC allowing for separation of overlapping reversing and non reversing events, such as glass transition and enthalpy recovery $[18,30,31]$ or post-cure processes. Dynamic glass transition is used to describe the increasing relaxation time in the stable or metastable equilibrium state [28]. It is usually determined in heating ramp by DSC or dynamic mechanical analysis (DMA). For frequencies in the Hertz range and higher, the temperature range is located above the glass transition temperature in thermodynamic (metastable) equilibrium [32]. DMA allows for evaluation of viscoelastic properties in polymers along a broad temperature range. Through the analysis of the damping factor, this technique provides one of the most reliable methods for measuring the dynamic glass transition temperature [33, 34].

There is some controversy about the $T_{g}$ determination by DSC on heating because, in most cases, an endothermic hysteresis peak is superimposed on the glass transition. Measurement of $T_{g}$ on cooling is recommended when using standard [29, 35]. Differences between $T_{g}$ measured by DSC on cooling and dynamic $T_{g}$ measured by DMA are due to the frequency effect on $T_{g}$ values. $T_{g}$ values obtained from $1 \mathrm{~Hz}$ DMA data for $E^{\prime \prime}$ or tan $\delta$ peak are always a few degrees higher than DSC $T_{g}$ values obtained at $10-20^{\circ} \mathrm{C} \mathrm{min}-1$ heating rates [35].

In this work, fumed silica-epoxy mixtures were prepared and characterized by thermal analysis methods. The properties of the non conventional epoxy resin, based on trimethylolpropane, make it particularly suitable for the manufacture of composites. Synthetic silicon dioxide (silica) can be produced either by precipitation or by apyrogenic (thermal) process. According to the method of production, synthetic silicon dioxides can be classified into two groups: precipitated and pyrogenic silica [36]. The fumed silica used here was obtained as a by-product of the silicon production in the top of large electrical melting furnaces, which is a non conventional production. Hence, the particle size and the purity of the fumed silica are variable, reflecting the furnace operation at the time it was collected. In any case, the silica weight proportion is greater than $95 \%$. According to Schadler, three dimensional nanofillers are relatively equally-axed particles, with a length lower than $100 \mathrm{~nm}$ in their largest dimension [17]. Hence, the fumed silica used in this work has its specific particle size distribution, including micro and nanoparticles. This makes it different from other micro or nanosized 
silica powders, and therefore, combined effects of both are expected.

The aim of this work is to evaluate the effects of fumed silica on both the curing and the viscoelastic properties of the resulting composites. Possible relations between the effect on the curing and the composite properties were considered and a statistical study was performed to this aim. Therefore, each experiment was replicated and several design of experiments (DOE) tests were applied: ANOVA table, $\mathrm{F}$ and Tukey.

\section{Experimental}

\subsection{Materials}

A two component epoxy system was used. It consisted of a diglicidyl ether of trimethylolpropane based resin, Triepox GA, from Gairesa (Valdoviño, Spain) and 1,3-benzenedimethanamine 99\% pure, from Aldrich (St. Louis, MO, USA), as curing agent. The 1,3-benzenedimethanamine is an aromatic amine hardener. Triepox GA is a highly thyxotropic resin with low density and curing capability at room temperature on its own, without either plasticizers or additives [37-39]. The epoxy resin was prepared by reaction of epichlorydrin with trimethylolpropane. The curing reaction scheme is presented in Figure 1 [37-39].

The fumed silica was provided by Ferroatlántica I+D (Arteixo, Spain). It was obtained as a by-product of the silicon production in electrical melting furnaces. This process involves the reduction of high purity quartz, at temperatures above $1800^{\circ} \mathrm{C}$. The silica fume is formed when the $\mathrm{SiO}$ gas, resulting from the reduction of quartz, is mixed with oxygen at the top of the furnace producing spherical silica particles. It is a fine powder with colour ranging from almost black to slightly-off white, depend- ing on its carbon content. Its mean particle size is $0.15 \mu \mathrm{m}$ and $41.9 \%$ of the particles have a diameter below $0.2 \mu \mathrm{m}$, as shown in Table 1. The SediGraph method was used for determining the mass distribution of particles as a function of particle size. This method has proved to be useful in many applications since 1967. Particle sizes were calculated from measurements of settling velocity and mass fraction, which was determined by relative absorption of low-energy X-ray [40]. The values obtained through surface area analysis typically fall about $20 \mathrm{~m}^{2} \cdot \mathrm{g}^{-1}$. Chemically, the fumed silica consists of amorphous $\mathrm{SiO}_{2}$ of variable purity. Some physical properties and chemical composition are shown in Table 2.

Table 1. Particle size distribution of the fumed silica

\begin{tabular}{|c|c|}
\hline Diameter $[\boldsymbol{\mu m}]$ & Mass [\%] \\
\hline $100-50$ & 1.2 \\
\hline $50-20$ & 2.0 \\
\hline $20-10$ & 0.2 \\
\hline $10-5$ & 0.5 \\
\hline $5-2$ & 1.4 \\
\hline $2-1$ & 1.5 \\
\hline $1-0.5$ & 8.3 \\
\hline $0.5-0.2$ & 43.0 \\
\hline$<0.2$ & 41.9 \\
\hline
\end{tabular}

Table 2. Some physical properties and chemical composition of the fumed silica

\begin{tabular}{|l|l|}
\hline Moisture $110^{\circ} \mathrm{C}$ & $0.50 \%$ \\
\hline Loss on calcination at $1000^{\circ} \mathrm{C}$ & $2.78 \%$ \\
\hline Real density & $2.26 \mathrm{~g} \cdot \mathrm{cm}^{-3}$ \\
\hline Apparent density & $0.66 \mathrm{~g} \cdot \mathrm{cm}^{-3}$ \\
\hline $\mathrm{SiO}_{2}$ & $+95 \%$ \\
\hline $\mathrm{CaO}$ & $0.68 \%$ \\
\hline $\mathrm{MgO}$ & $0.22 \%$ \\
\hline $\mathrm{Na}_{2} \mathrm{O}$ & $0.10 \%$ \\
\hline $\mathrm{K}_{2} \mathrm{O}$ & $0.22 \%$ \\
\hline $\mathrm{Cl}$ & $0.006 \%$ \\
\hline $\mathrm{SO}_{4}$ & $0.076 \%$ \\
\hline
\end{tabular}<smiles></smiles><smiles></smiles>

Figure 1. Chemical reaction scheme of the curing of Triepox GA with amine hardeners 


\subsection{Sample preparation}

Filler-resin mixtures for curing studies:

For the curing study, samples of the resin containing $0,10,20,30,40$ and $50 \mathrm{wt} \%$ of fumed silica were prepared, with the aim of measuring the heat of reaction by DSC. The resin and the curing agent were poured at stoichiometric proportions and manually stirred for 2 minutes. Then, the adequate amount of silica was added and mixed again for 5 minutes. In order to prevent any volatilization process, the samples were encapsulated in hermetic aluminium DSC crucibles. The mass of the samples was adjusted so that the resin content was close to $3.18 \mathrm{mg}$, independently of the filler content.

\section{Cured samples:}

Composite samples for DMA tests were prepared with filler contents of 5,10,20,30,40, 50 and $60 \mathrm{wt} \%$ of fumed silica. Both the epoxy resin and the hardener were mixed in stoichiometric proportions. Resin and silica mixtures were stirred for 15 minutes in order to obtain a uniform distribution. Then, a sonication treatment was applied for 5 minutes at room temperature to disperse the filler agglomerates. The composite paste was poured into a silicone mould whose cavity dimensions were $0.8 \times 4 \times 30 \mathrm{~mm}$. This resin was reported to cure at room temperature having a $T_{g}$ about $90^{\circ} \mathrm{C}$. In this work, the samples were cured at room temperature for 24 hours and post-cured in an oven at $90^{\circ} \mathrm{C}$ for 2 hours. Further MDSC analysis showed the adequacy of this procedure. The specimens were finally cut, by scissors, to a length of $10 \mathrm{~mm}$, so that their lengths do not protrude in excess the DMA fixtures. For the DSC and MTDSC-glass transition tests and for the TG stability study, cured samples were cut from DMA samples. The sample mass was adjusted so that each sample contained about $3 \mathrm{mg}$ of resin, independently of the filler content.

\subsection{Characterization methods}

The DSC experiments were performed on a TA Instruments (headquartered in New Castle, DE, USA) MDSC Q-1000 attached to a refrigerating cooling system. This instrument can be operated in both modulated and standard modes. The following calibrations were performed, according to manufacturer recommended procedures: $T_{z e r o}$, enthalpy constant, temperature and modulated heat capacity. A range of temperature from -20 to $300^{\circ} \mathrm{C}$ was chosen, as per recommendations from the literature [18]. Sapphire standard and crimped aluminum crucibles were used for heat capacity calibration in modulated conditions.

The curing experiments were performed by standard DSC using hermetic aluminium crucibles to prevent hardener volatilization. A $10^{\circ} \mathrm{C} \cdot \mathrm{min}^{-1}$ heating ramp was applied from -20 to $220^{\circ} \mathrm{C}$.

The $T_{g}$ of the cured samples was also determined by DSC in standard mode, although in this case a $10^{\circ} \mathrm{C} \cdot \mathrm{min}^{-1}$ cooling ramp from 110 to $0^{\circ} \mathrm{C}$ was used. A previous thermal stability study of these composites [26] was considered in order to determine a range of temperature where the material does not decompose.

DSC was operated in modulated mode in order to separate the reversing $\mathrm{Cp}$ from non reversing phenomena such as enthalpic recovery, residual cure and possible degradation processes taking place in cured samples. The thermal program consisted of a $5^{\circ} \mathrm{C} \cdot \mathrm{min}^{-1}$ average heating ramp from -20 to $200^{\circ} \mathrm{C}$. The modulation amplitude was $1.6^{\circ} \mathrm{C}$ and the period $60 \mathrm{~s}$.

The viscoelastic properties of the cured composites were evaluated by DMA on a DMTA IV instrument manufactured by the company Rheometric Scientific (Piscataway, NJ, USA). Calibration was performed as per manufacturer recommendations included in the Rheometric Orchestrator ${ }^{\mathrm{TM}}$ software. The tests were conducted in tensile mode. The samples were about $0.8 \mathrm{~mm}$ thick and $4 \mathrm{~mm}$ width. A fixture gap of $10 \mathrm{~mm}$ was used. A strain sweep test was performed at room temperature in order to find experimental conditions in the viscoelastic linear region for subsequent experiments. This was done by varying the strain amplitude while keeping the frequency at $1 \mathrm{~Hz}$. A strain amplitude of $0.005 \%$ and $1 \mathrm{~Hz}$ frequency were chosen. A constant heating ramp of $2^{\circ} \mathrm{C} \cdot \mathrm{min}^{-1}$ was applied in all the experiments.

An additional TGA experiment was performed with a cured composite sample in order to verify some possible degradation process observed in the MTDSC experiments. The test was performed on a STA 1500 Rheometric Scientific thermo balance (Piscataway, NJ, USA). A heating ramp of $10^{\circ} \mathrm{C} \cdot \mathrm{min}^{-1}$ was applied in the range from 20 to 
$600^{\circ} \mathrm{C}$, at a rate of $50 \mathrm{ml} \cdot \mathrm{min}^{-1}$ of $\mathrm{N}_{2}$. Upon reaching $600^{\circ} \mathrm{C}$, the purge was changed to air and isothermal condition was kept for 4 minutes.

Particle distribution and dispersion in the matrix were studied by scanning electron microscopy. DMA specimens were previously broken manually. The fracture surface was coated with a thin layer of gold in a sputtering equipment BALTEC SCD 004 and then analyzed in a scanning electron microscope JSM-6400 (JEOL, Tokyo, Japan) equipped with a system of chemical microanalysis by energy dispersive X-ray Oxford INCA ENERGY 200 (Oxford Instruments, Abingdon, Oxfordshire, UK). It has been performed a TEM analysis for studying the distribution of particle sizes and dispersion with a greater magnification. TEM analysis has been realized in a transmission electron microscope JEM-1010 (JEOL, Tokyo, Japan). The sections observed under the microscope (with a thickness of about $80 \mathrm{~nm}$ ) were obtained in a Reichert ultramicrotome Ultracut E (Reichert, Depew, NY, USA).

\subsection{Experimental design}

An experimental design was applied to evaluate the filler content effects on the heat of curing of the fresh mixtures and the $T_{g}$ of the cured samples. A one-way design was chosen to test for differences in the response among the independent groups. The silica content was the chosen factor or independent variable. A fixed-effects model of analysis of variance (ANOVA) was applied. The value of the explanatory variable was varied in order to see how the response variable changes, and to test if there are testing significant differences in the response. It also allows for estimation of the variation ranges of the responses produced by the filler content. The responses considered were the heat of reaction, the $T_{g}$, measured by DSC in cooling, and the dynamic $T_{g}$, determined by DSC in heating. The following levels of filler content were considered for the heat of curing study: $0,10,20,30,40$ and $50 \mathrm{wt} \%$. The $5 \mathrm{wt} \%$ level was also included for the $T_{g}$ study in order to increase the resolution of the analysis in the low filler content range. All the experiments were replicated in order to estimate the variability.

\section{Results and discussion}

\subsection{Evaluation of the curing by DSC}

Figure 2 plots an overlay of the DSC curves obtained from the curing experiments. A broad exotherm corresponding to the curing reaction can be observed in each curve. The curing enthalpy, $\Delta H_{R X N}$, was calculated by dividing the area of the exotherm peak by the resin content of the sample. An ANOVA test was performed to discern if the silica content factor produces significant differences in the response, $\Delta H_{R X N}$. The Tukey test was applied to determine what particular proportions of silica produce significant differences in the response respect to the other levels of silica [41-43]. This test can only be applied when observations are independent, variances on the response are equal across groups and the response or dependent variable is normally distributed in each group. Normality was tested by the Shapiro Wilk test $(\mathrm{P}$-value $=0.16>0.05)[44]$, homoscedasticity by the Bartlett one (P-values $=0.769>0.05)$ [45] and independence by the Durbin-Watson test $(\mathrm{P}$-value $=$ $0.966>0.05)[46,47]$. The ANOVA and $F$ test have shown that there are significant differences in $\Delta H_{R X N}$ when varying the amount of silica $(\mathrm{P}$-value $=$ $\left.6.873 \cdot 10^{-11}<0.05\right)$ assuming a significance level of 0.05 . Therefore the $\Delta H_{R X N}$ response actually depends on the silica content.

Moreover, the Tukey test was applied to find out which specific means of $\Delta H_{R X N}$, at each silica level, are different from the others. The results (P-values $<$ $0.05)$, indicate that the six groups are significantly

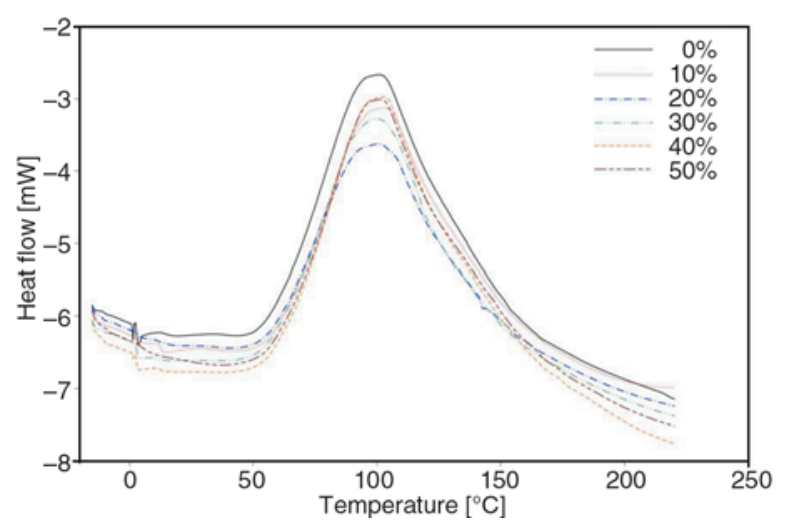

Figure 2. DSC curves obtained from the curing experiments with different wt $\%$ of fumed silica 
Table 3. Results obtained from the DSC curing experiments

\begin{tabular}{|c|c|c|}
\hline $\begin{array}{c}\text { Silica content } \\
{[\mathbf{w t} \%]}\end{array}$ & $\begin{array}{c}\text { Sample mass } \\
{[\mathbf{m g}]}\end{array}$ & $\begin{array}{c}\Delta \mathbf{H}_{\mathbf{R X N}} \\
{\left[\mathbf{J} \cdot \mathbf{g}^{-1}\right]}\end{array}$ \\
\hline 0 & 3.18 & $440.1 \pm 0.1$ \\
\hline 10 & 3.90 & $429.5 \pm 1.3$ \\
\hline 20 & 3.95 & $379.6 \pm 1.3$ \\
\hline 30 & 4.50 & $436.1 \pm 0.1$ \\
\hline 40 & 5.52 & $491.8 \pm 0.7$ \\
\hline 50 & 6.28 & $496.7 \pm 0.7$ \\
\hline
\end{tabular}

different. Then, the $\Delta H_{R X N}$ averaged values presented in Table 3 are significantly different.

It can be observed in Table 3 that $\Delta H_{R X N}$ increases with the silica content for contents above the $30 \mathrm{wt} \%$, which indicates that the resin may react with the filler. The opposite effect can be observed for silica contents below the $30 \mathrm{wt} \%$, indicating an incomplete cross linking due to the presence of particles. It suggests that agglomerates of particles are formed and these agglomerates could absorb part of

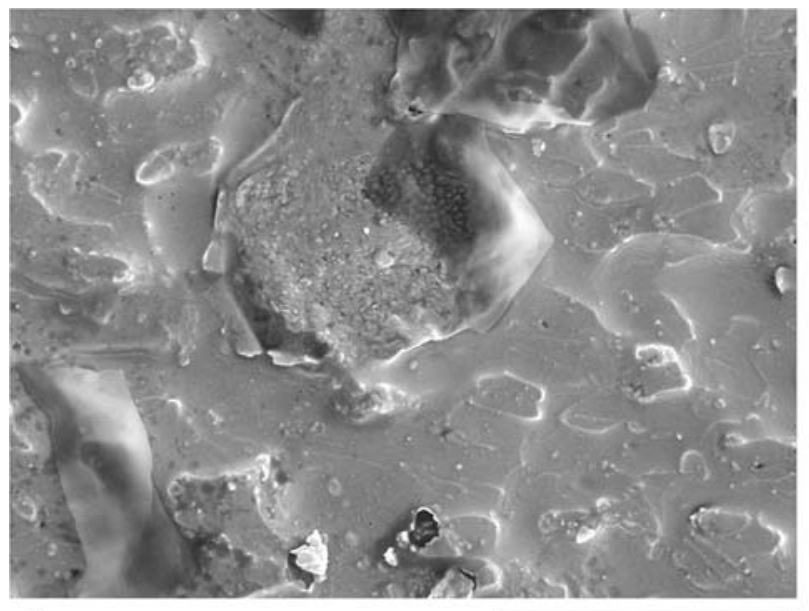
a)

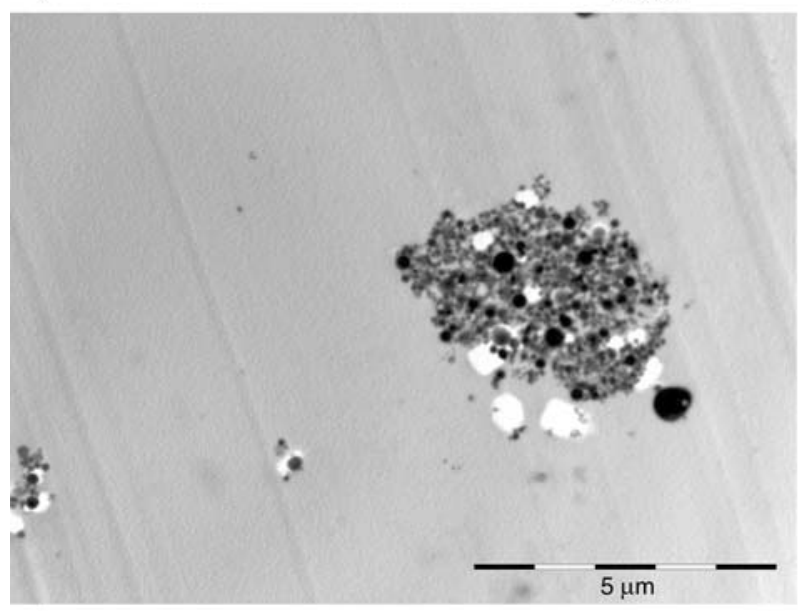

c) the hardener. Thus, the stoichometric balance would be distorted resulting in an incomplete cure.

\subsection{Morphological study of cured composites}

A morphological study of composite samples with 5,30 and $40 \mathrm{wt} \%$ of filler was performed by SEM and TEM. Few areas containing agglomerates and single particles could be found in the $5 \mathrm{wt} \%$ sample. The first two micrographs in Figure 3 show two of these areas. The first SEM micrograph shows an uncovered agglomerate surrounded by smaller agglomerates, which are covered by the polymer matrix. It can be observed that the agglomerate seems to be mostly composed of nanosized particles, although a particle of about one $\mu \mathrm{m}$ is located at its center. The shape and size of the agglomerates is variable. The second SEM micrograph shows some single microparticles, which are spherical in shape, although of very different sizes. It was considered convenient to complete the mor-

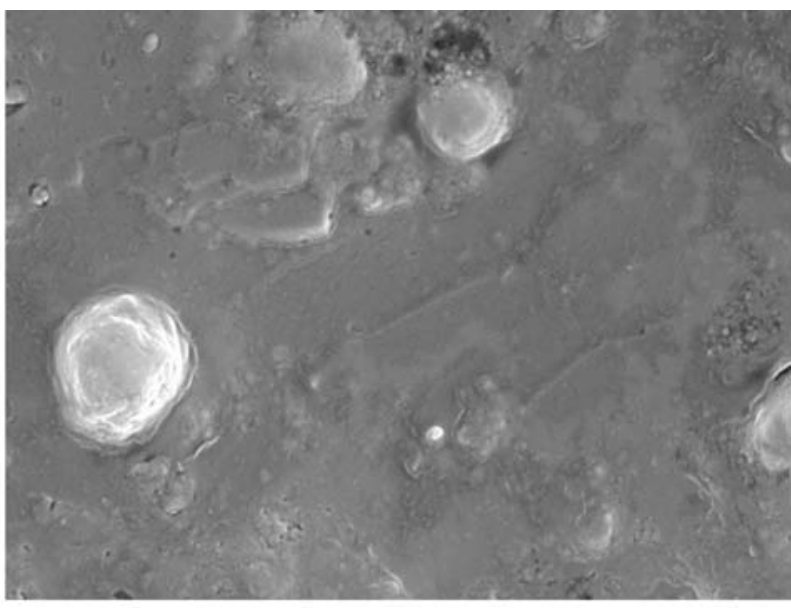

b)

$10 \mu \mathrm{m}$

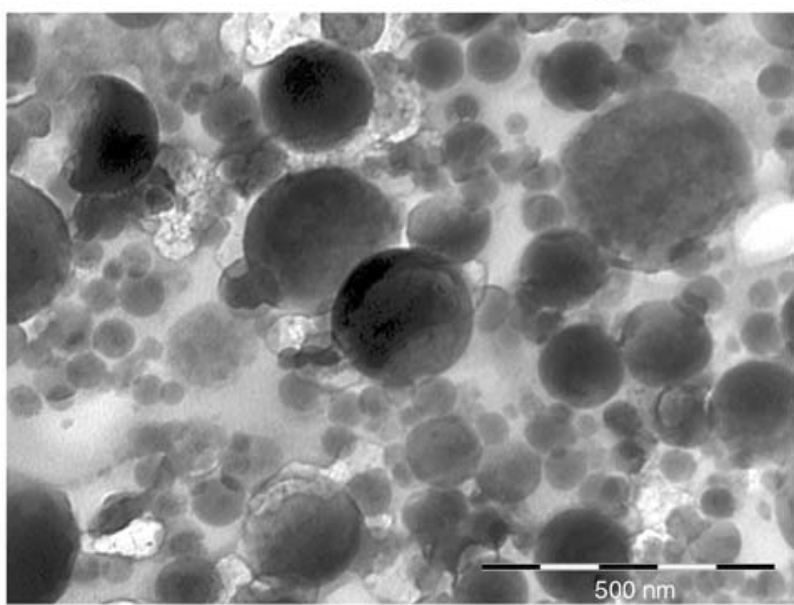

d)

Figure 3. SEM micrographs obtained from the fracture surface (a, b) and TEM micrographs (c, d) of a 5 wt $\%$ filler sample 


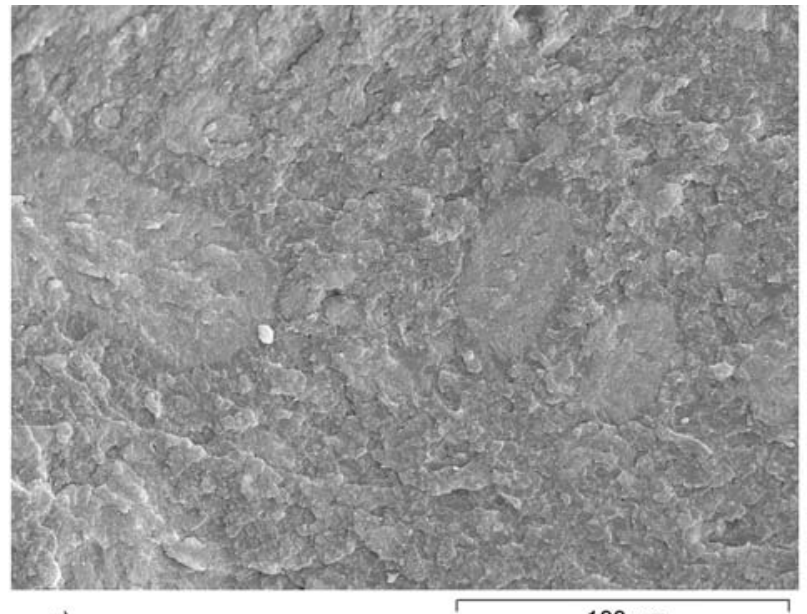

a)

$100 \mu \mathrm{m}$

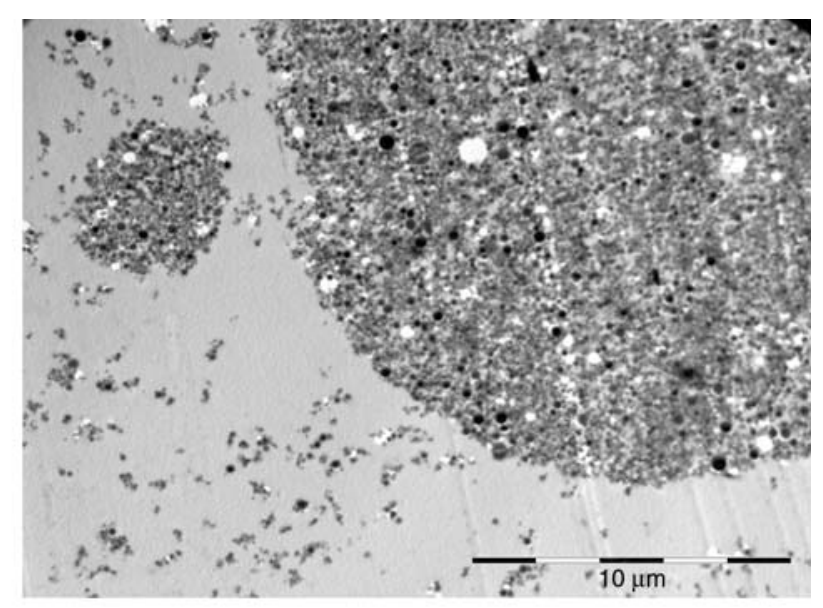

b)

Figure 4. SEM micrographs obtained from the fracture surface of a $30 \mathrm{wt} \%$ sample (a) and TEM micrograph (b)

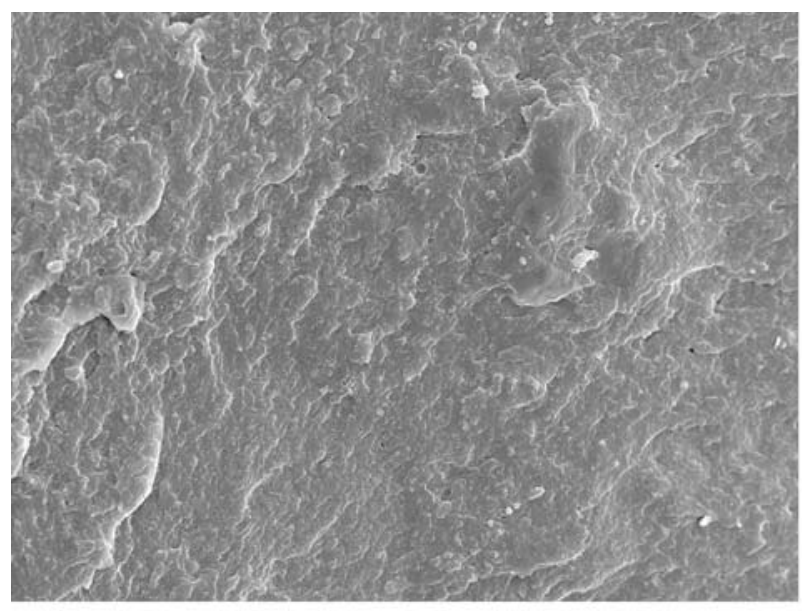

a)

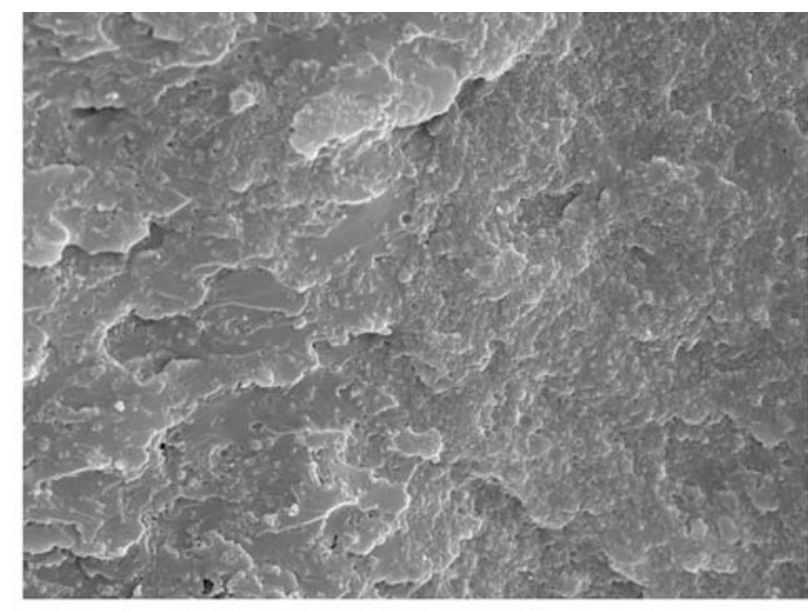

b)

$10 \mu \mathrm{m}$

Figure 5. SEM micrographs obtained from a $40 \mathrm{wt} \%$ sample $(\mathrm{a}, \mathrm{b})$

phological study by TEM to confirm the SEM observations. So, the third and fourth micrographs in Figure 3 show that the agglomerates are mostly composed of nanosized particles. The first micrograph in Figure 4, obtained by SEM, shows one region on the fracture surface, belonging to the $30 \mathrm{wt} \%$ sample. Some elliptical regions can be observed. The energy dispersive X-ray (EDX) analysis of these regions indicates high silica content. In contrast, the surrounding regions present very low silica content. It indicated that the fumed silica particles are not uniformly dispersed but agglomerated in the elliptical regions. TEM analysis supports and complements SEM analysis in the second micrograph in Figure 4. Moreover, it shows that the agglomerates grow when compared with those in the $5 \mathrm{wt} \%$ sample (Figure 3, third micrograph). The micrographs in Figure 5, obtained by SEM, show the fracture surface of a $40 \mathrm{wt} \%$ sam- ple, at two different magnifications. The elliptical formations disappeared and no agglomerates were found, indicating that the filler is well distributed over the entire sample. Single particles can be observed in the second picture. Figure 6 shows a SEM micrograph corresponding to a $40 \mathrm{wt} \%$ sample and its corresponding silica particle dispersion map, obtained by X-ray. Silica particles are well dispersed although non-uniformly distributed over the region. That non-uniformity was only observed at the low scale. Morphologically, two regions can be distinguished. The one corresponding to the higher silica content is rough, with no apparent plastic deformation, indicating a brittle fracture. On the contrary, the lower filler content region presents some plastic deformation, indicating a somewhat ductile fracture.

These morphological results match the hypothesis drew from the curing study, so that the agglomer- 

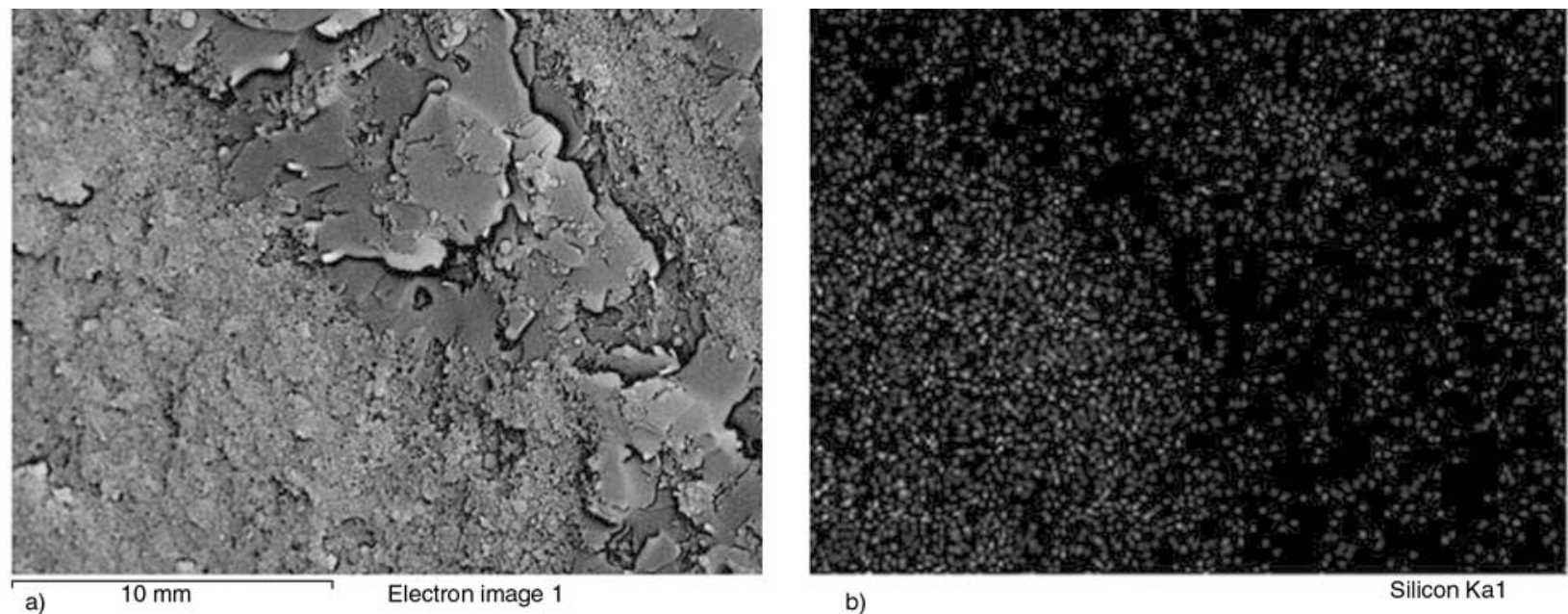

b)

Silicon Ka1

Figure 6. SEM micrograph corresponding to a region in a sample with an amount of $40 \mathrm{wt} \%$ of silica (a) and its silica particles dispersion map, obtained by X-ray (b)

ates would act as hardener captors and the well dispersed particles would react with the resin.

\subsection{Effects on the properties of cured composites}

Figure 7 shows the non-reversing heat flow plots obtained by MTDSC from the cured samples. An exotherm, starting at about $115^{\circ} \mathrm{C}$, indicates the beginning of sample degradation, what was confirmed by TGA, as it can be observed in Figure 8 . But there is no trace of residual cure. It means that the curing and post curing treatments were enough to fulfil the cure completion. Figure 8 plots the TGA curves obtained in $\mathrm{N}_{2}$ atmosphere, with change to air at $600^{\circ} \mathrm{C}$. A small increase of the sample mass is observed at the beginning of the experiment. It was reported that this phenomenon can be attributed to a buoyancy effect due to a decrease of the atmosphere density as the temperature raises

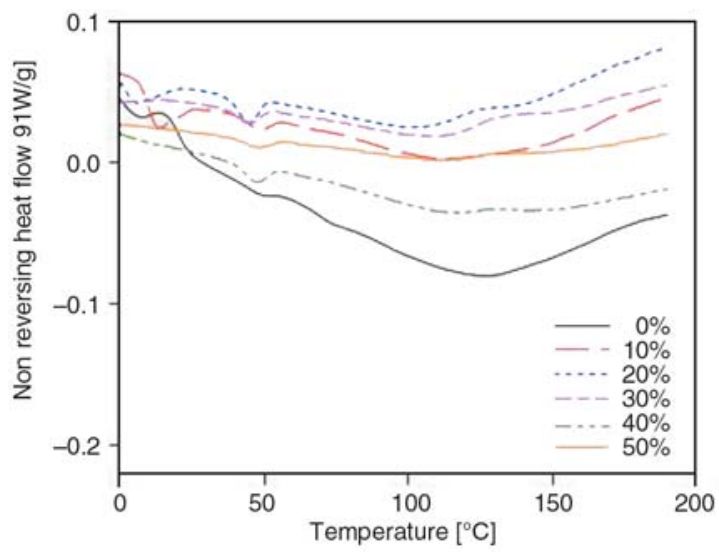

Figure 7. Specific non reversing heat flow curves obtained with the different samples

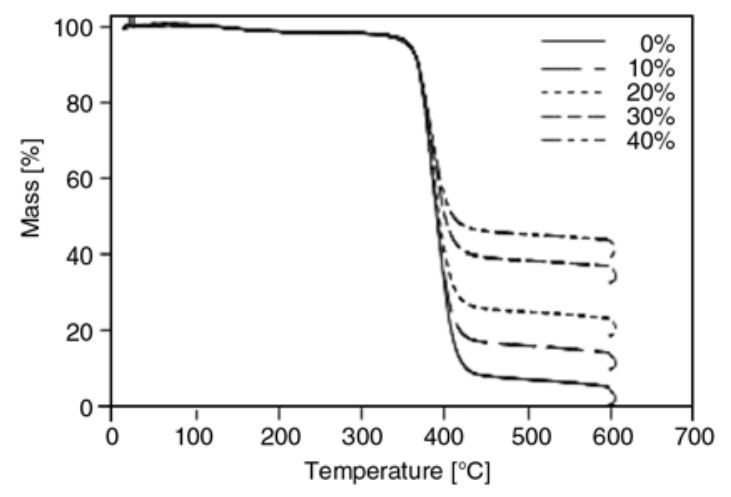

Figure 8. TGA curves obtained from the neat epoxy thermoset and composites with different fumed silica contents in $\mathrm{N}_{2}$ atmosphere. Upon reaching $600^{\circ} \mathrm{C}$, isothermal condition was established and the purge was changed to air.

[35]. Nevertheless, considering that this phenomenon was not observed in other experiments, performed under the same experimental conditions but with different materials, the buoyancy effect does not seem to be responsible of that mass gain. Thus, it indicates that the sample absorbs nitrogen from the purge flow. There is also a mass loss in the range from 100 to $200^{\circ} \mathrm{C}$. It is higher than the increase due to $\mathrm{N}_{2}$ absorption, and indicates a decomposition process of the weakest structure of the sample, which extends up to about $300^{\circ} \mathrm{C}$, overlapping with the main degradation process. The residue obtained after the isothermal stage in air at $600^{\circ} \mathrm{C}$ corresponds to the filler content, indicating a complete combustion of the char.

Figure 9 shows the storage modulus, $E^{\prime}$, loss modulus, $E^{\prime \prime}$, and damping factor, $\tan \delta$, obtained in a DMA temperature ramp from a cured sample. The 


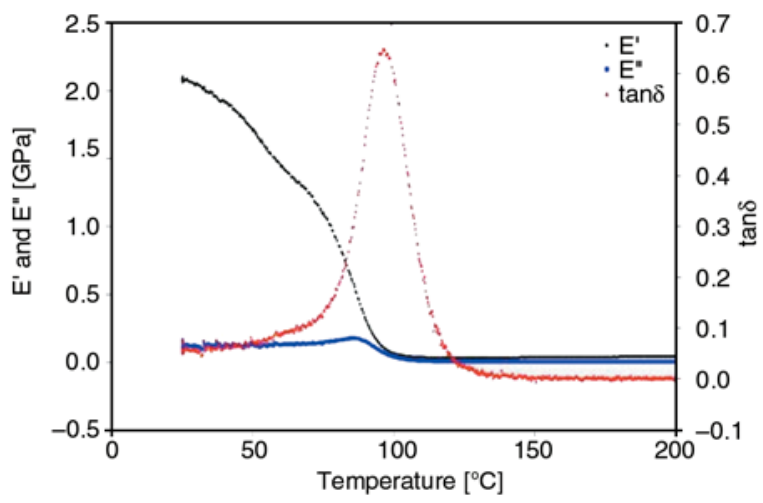

Figure 9. $E^{\prime}, E^{\prime \prime}$ and $\tan \delta$ curves obtained by DMA from the neat resin sample

$E^{\prime}$ decrease observed in a range from 50 to $100^{\circ} \mathrm{C}$ correspond to the glass transition relaxation of the polymer. The $T_{g}$ is also evidenced by a small peak of $E^{\prime \prime}$ and by a well defined peak of tan $\delta$. Thus, the maximum peak value of $\tan \delta$ was the chosen criterion to compare the $T_{g}$ values obtained by DMA. It can be observed in Figure 10 that, in all cases, $E^{\prime}$ decreases monotonically with any temperature increment, at temperatures below the $T_{g}$. This can be attributed in part to the softening of the polymer matrix, which is more apparent in the proximity of $T_{g}$, as it can be observed on the unfilled curve, and in part, to the difference between the coefficients of thermal expansion of the matrix and the fumed silica, inducing relaxations in the polymer phase, as was reported in other studies $[6,8,10]$. Above the $T_{g}, E^{\prime}$ increases with the temperature, indicating a stiffening process of the matrix. It is probably due to an incipient degradative process, which is consistent with the TGA behavior observed at temperatures below $300^{\circ} \mathrm{C}$. The slope of the $E^{\prime}$ curve does not change appreciably, which is in line with existing studies [8].

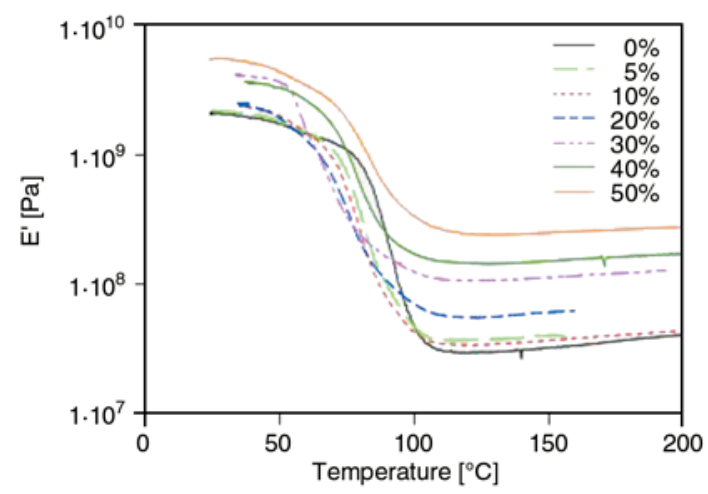

Figure 10. $E^{\prime}$ plots obtained from the neat resin and composites with different fumed silica contents

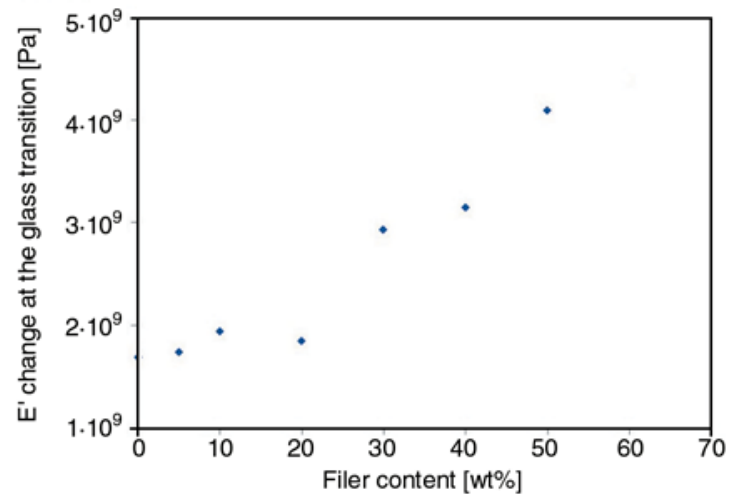

Figure 11. Change of $E^{\prime}$ observed for different filler contents in the temperature range of 50 to $150^{\circ} \mathrm{C}$

Figure 10 also shows a stiffening effect of the fumed silica addition, which seems to be more noticeable above the glass transition temperature. Nevertheless, it is only apparent, due to the use of a semi-logarithmic scale. In Figure 11, the $E^{\prime}$ change in the temperature range of 50 to $150^{\circ} \mathrm{C}$ is plotted vs. the filler content. It can be observed that the $E^{\prime}$ drop at the glass transition increases very slightly up to the $20 \mathrm{wt} \%$. Above the $30 \mathrm{wt} \%$, an important increasing trend with the filler content is observed. Since the glass transition is associated to the polymer phase, the opposite behavior could be, in principle, expected. Nevertheless, it can be understood as an indication that the silica induces some changes in the polymer matrix so that the higher the filler content the higher the fraction of the matrix undergoing some kind of relaxation at the glass transition. Particularly, the change of trend observed at the $30 \mathrm{wt} \%$ can be easily related to the dispersion of nanoparticle elliptical agglomerates, which was described in the morphological study part. Any increase of the filler amount, below the $20 \mathrm{wt} \%$, would mainly produce an increase of the agglomerate size, providing little contribution to an effective filler-polymer surface increment. Nevertheless, in the range from 30 to $40 \mathrm{wt} \%$, the agglomerates are destroyed, due to the higher viscosity and thus to the higher shear stresses generated in the stirring sample preparation stage. Any increment in the filler content, above the $30 \mathrm{wt} \%$, will produce a neat increment of the amount of filler-polymer interphase.

A plasticizing effect of the filler can be observed in Figure 12, where all the filled samples present a shifting of the $\tan \delta$ peaks to lower temperatures with respect to the neat resin sample, according to 
Table 4. $T_{g}$ values obtained by DSC on cooling and DMA on heating. The area and normalized area of the tan $\delta$ peaks obtained by DMA are also shown.

\begin{tabular}{|c|c|c|c|c|}
\hline $\begin{array}{c}\text { Silica content } \\
{[\mathbf{w t} \%]}\end{array}$ & $\begin{array}{c}\mathbf{T}_{\mathbf{g}} \text { DSC (cooling) } \\
{\left[{ }^{\circ} \mathbf{C}\right]}\end{array}$ & $\begin{array}{c}\mathbf{T}_{\mathbf{g}} \text { DMA (heating) } \\
{\left[{ }^{\circ} \mathbf{C}\right]}\end{array}$ & $\begin{array}{c}\tan \boldsymbol{\delta} \text { peak area } \\
{[\mathbf{s}]}\end{array}$ & $\begin{array}{c}\text { Normalized tan } \boldsymbol{\delta} \text { peak area } \\
{[\mathbf{s}]}\end{array}$ \\
\hline 0 & $77.6 \pm 0.6$ & 96.7 & 430.8 & 430.8 \\
\hline 5 & $66.7 \pm 1.0$ & 83.7 & 413.9 & 435.7 \\
\hline 10 & $66.9 \pm 1.3$ & 81.8 & 396.0 & 440.0 \\
\hline 20 & $63.3 \pm 1.1$ & 77.4 & 363.2 & 454.0 \\
\hline 30 & $62.1 \pm 0.6$ & 70.6 & 324.0 & 462.9 \\
\hline 40 & $65.0 \pm 0.7$ & 81.6 & 319.9 & 533.1 \\
\hline 50 & $68.2 \pm 1.3$ & 85.8 & 280.9 & 561.8 \\
\hline
\end{tabular}

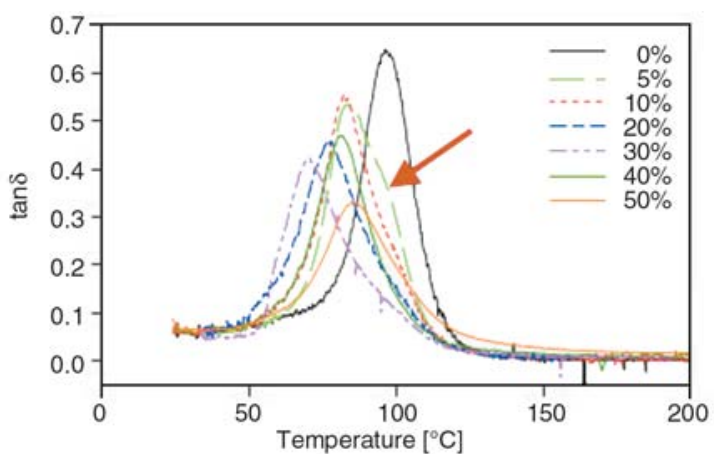

Figure 12. $\tan \delta$ curves obtained from composites with different filler contents. A shoulder on the right side of $\tan \delta$ peak is pointed out by an arrow.

Huang and Lee study [10]. Another effect of the filler is a broadening of the $\tan \delta$ peaks. This indicates higher heterogeneity of the composites crosslinked structure [35]. In Table 4, it can be observed that the area of the peaks decreases when the silica content is increased. Since the glass transition is a relaxation process of the polymer, the lower the polymer content, the lower the magnitude of the glass transition change. A shoulder can be observed on the right side of the tan $\delta$ peaks of the composites. It is more evident on the $5 \mathrm{wt} \%$ curve. Reed [48] suggested that the existence of a shoulder can be attributed to the particle-resin interface, which is different from the polymer matrix [18]. In this case, the composites shoulder is located at the $T_{g}$ of the unfilled material. It would indicate that the shoulder represents the glass transition of the polymer segments not affected by the filler, while the interface material has a lower $T_{g}$. At the filler contents considered in this work, it is clear that the magnitude of the interface glass transition is higher than that corresponding to the fraction of the matrix free from the filler effect. Nevertheless, a different relation should be expected for filler contents well below the $5 \mathrm{wt} \%$. Table 4 also shows the normalized values of the $\tan \delta$ peak areas, which were obtained by division of the areas by the polymer fraction. The normalized tan $\delta$ area increases with the filler content up to the $50 \mathrm{wt} \%$. It can be explained as an effect of the effective polymerfiller interfacial area, which increases with the filler content. The maximum difference is observed in the 30 to $40 \mathrm{wt} \%$ range, which corresponds to the agglomerates destruction and thus, to a dramatic increase of the interface area.

Table 4 shows the $T_{g}$ values obtained by DSC and DMA. The DSC $T_{g}$ values were calculated from the heat flow curves shown in Figure 13, which were performed in standard DSC mode, in cooling, according to recommendations from the literature [35], while the DMA values were taken at the maximum of $\tan \delta$ peak [35] from heating ramp experiments. Under hypothesis previously explained, the DMA $T_{g}$ values of the composites are mainly contributed by the interface glass transition, while in the case of the neat thermoset such interface does not exist. The $T_{g}$ values obtained by DSC are always lower than the corresponding ones obtained by DMA. This difference comes from the fact that these techniques measure different properties and the DMA results are affected by the frequency effect.

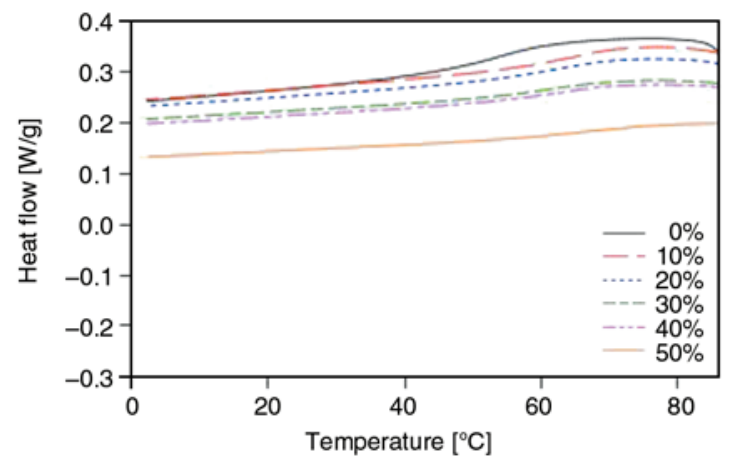

Figure 13. Specific heat flow curves obtained from the different composites by DSC operated in standard cooling ramp 
A statistical study was done in order to determine the reliability of these results. Therefore, each experiment has been replicated. ANOVA was applied to discern whether the silica content produces significant differences in the response. In order to verify the model hypothesis, normality was tested by the Shapiro Wilk test $(\mathrm{P}$-value $=0.03$ $<0.05$ ) [44], homoscedasticity by Bartlett (P-values $=0.9995>0.05)[45]$ and independence by Durbin-Watson $(\mathrm{P}$-value $=0.997>0.05)[46,47]$. Although, normality is in the limit of significance, ANOVA is robust even if the dependent variable data are approximately normally distributed [41]. So, the ANOVA and the F test revealed that there are significant differences in $T_{g}$ when varying the amount of silica (P-value $\left.=1.419 \cdot 10^{-5}<0.05\right)$. Moreover, the coefficient of determination $\left(R^{2}=\right.$ 0.9797) indicates that mean differences of the amount of silica explain the $T_{g}$ variability. The result from the Tukey test, Table 5 , revealed that there are four groups with significantly different $T_{g}$. The neat epoxy material is statistically different from the rest of the samples. The $30 \mathrm{wt} \%$ composite is also significantly different from the rest of the samples. The increase of $T_{g}$ observed in the 40 and $50 \mathrm{wt} \%$ samples and the difference between the 40 and $50 \mathrm{wt} \%$ are also significant.

Both DMA and DSC $T_{g}$ values indicate that, in general, although the $T_{g}$ values measured in the composites were always lower than that obtained from the unfilled sample, opposite effects exist below and above $30 \mathrm{wt} \%$ of filler. While additions of filler up to $30 \mathrm{wt} \%$ produce a continuous decrease of the $T_{g}$, increments from 30 to $50 \mathrm{wt} \%$ result in an increase of $T_{g}$. It can be again related to the dispersion of nanoparticle elliptical agglomerates, which was clearly observed in the $30-40 \mathrm{wt} \%$ filler content range. In this case, increments of the filler content, below the $20 \mathrm{wt} \%$, would mainly produce an

Table 5. Silica content groups resulting to be different according to the Tukey analysis of the $T_{g}$ values

\begin{tabular}{|c|c|c|c|c|}
\hline \multirow{2}{*}{$\begin{array}{c}\text { Silica content } \\
{[\mathbf{w t} \%]}\end{array}$} & \multicolumn{4}{|c|}{ Significance level = 0.05 } \\
\cline { 2 - 5 } & $\mathbf{1}$ & $\mathbf{2}$ & $\mathbf{3}$ & $\mathbf{4}$ \\
\hline 30 & 62.1 & & & \\
\hline 20 & 63.3 & 63.3 & & \\
\hline 40 & 65.0 & 65.0 & 65.0 & \\
\hline 5 & & 66.7 & 66.7 & \\
\hline 10 & & 66.9 & 66.9 & \\
\hline 50 & & & 68.2 & \\
\hline 0 & & & & 77.6 \\
\hline P-values & 0.152 & 0.058 & 0.090 & 1.000 \\
\hline
\end{tabular}

increase of the agglomerates amount and size, providing little contribution to an effective filler-polymer surface increment. These agglomerates would act as small bubbles, providing a plasticizing effect. Nevertheless, in the range from the 30 to the $40 \mathrm{wt} \%$, the agglomerates are destroyed, and any increment of the filler content, above the $30 \mathrm{wt} \%$, will produce a neat increment of the filler-polymer interfacial area resulting in an increase of $T_{g}$. Increments above the $50 \mathrm{wt} \%$ seem to produce a slight decrease of $T_{g}$, indicating some discontinuity of the polymer matrix, which would not be sufficient to surround all the particles and agglomerates. The fact that the $T_{g}$ of the high filler content composites is still lower than the one of the neat resin indicates a plasticizing effect of the well dispersed particles, which is much lower than the plasticization produced by the agglomerates.

\section{Conclusions}

The curing study suggests that the agglomerates would act as hardener captors and the well dispersed particles would react with the resin. It matches perfectly with the morphological results. The morphological study confirmed that the particles tend to agglomerate when its content is lower than the $30 \mathrm{wt} \%$. Higher filler content produce well dispersed composites. It is related to the viscosity of the mixture and the shear stresses generated in the preparation of the mixtures. According to the micrographs, the agglomerates appear to be mostly composed of nanoparticles.

Two glass transition processes were identified, although not resolved, by DMA in the composites. One seems to correspond to the polymer fraction not interacting with the filler and occurs at the same temperature that the glass transition of the pristine thermoset. The other seems to correspond to the interface. The latter is predominant at the $5 \mathrm{wt} \%$ and higher filler contents and thus, it is the responsible of the plasticization effects identified by the glass transition temperature studies.

The glass transition temperature studies revealed two plasticization effects of the fumed silica. Both effects are reflected in the interface glass transition, which predominates over the neat polymer one at the $5 \mathrm{wt} \%$ and higher filler contents. One plasticizing effect is produced by the particle agglomerates and the other by the well dispersed particles. The 
plasticizing effect of the agglomerates is much stronger than the produced by the dispersed particles. The agglomerates effect predominates at filler contents below the $30 \mathrm{wt} \%$ while the dispersed particles effect is predominant at higher filler contents. DSC results suggest that a slight degradation process starts at $115^{\circ} \mathrm{C}$ independently of the filler content. This is in line with a stiffening effect of the temperature observed by DMA. Finally, this degradation process was confirmed by TG.

\section{Acknowledgements}

This work was partially funded by the Spanish Ministerio de Educación y Ciencia MTM2008-00166. Thanks to Antonio Pérez from Ferroatlántica and Senén Paz from Gairesa for their comments about fumed silica and epoxy resin.

\section{References}

[1] Harsch M., Karger-Kocsis J., Holst M.: Influence of fillers and additives on the cure kinetics of an epoxy/ anhydride resin. European Polymer Journal, 43, 11681178 (2007). DOI: $\underline{10.1016 / j . e u r p o l y m j .2007 .01 .025}$

[2] Lee A., Lichtenhan J. D.: Thermal and viscoelastic property of epoxy-clay and hybrid inorganic-organic epoxy nanocomposites. Journal of Applied Polymer Science, 73, 1993-2001 (1999).

DOI: $10.1002 /($ SICI $) 1097-4628(19990906) 73: 10$ $\leq 1993:$ :AID-APP18>3.0.CO;2-Q

[3] Hsiue G-H., Chen J-K., Liu Y-L.: Synthesis and characterization of nanocomposite of polyimide-silica hybrid from nonaqueous sol-gel process. Journal of Applied Polymer Science, 76, 1609-1618 (2000).

DOI: 10.1002/(SICI) 1097-4628(20000613)76:11 $\leq 1609::$ AID-APP1 $>3.0 . \mathrm{CO} ; 2-\mathrm{W}$

[4] Mehta S., Mirabella F. M., Rufener K., Bafna A.: Thermoplastic olefin/clay nanocomposites: Morphology and mechanical properties. Journal of Applied Polymer Science, 92, 928-936 (2004).

DOI: 10.1002/app.13693

[5] Fu S-Y., Feng X-Q., Lauke B., Mai Y-W.: Effects of particle size, particle/matrix interface adhesion and particle loading on mechanical properties of particulate-polymer composites. Composites Part B: Engineering, 39, 933-961 (2008).

DOI: 10.1016/j.compositesb.2008.01.002

[6] Zhang H., Zhang Z., Friedrich K., Eger C.: Property improvements of in situ epoxy nanocomposites with reduced interparticle distance at high nanosilica content. Acta Materialia, 54, 1833-1842 (2006).

DOI: $\underline{10.1016 / \mathrm{j} . \text { actamat.2005.12.009 }}$
[7] Liu Y-L., Wei W-L., Hsu K-Y., Ho W-H.: Thermal stability of epoxy-silica hybrid materials by thermogravimetric analysis. Thermochimica Acta, 412, 139 147 (2004).

DOI: $10.1016 /$ j.tca.2003.09.004

[8] Preghenella M., Pegoretti A., Migliaresi C.: Thermomechanical characterization of fumed silica-epoxy nanocomposites. Polymer, 46, 12065-12072 (2005). DOI: $10.1016 /$ j.polymer.2005.10.098

[9] Yousefi A., Lafleur P. G., Gauvin R.: Kinetic studies of thermoset cure reactions: A review. Polymer Composites, 18, 157-168 (1997). DOI: $10.1002 /$ pc. 10270

[10] Huang G. C., Lee J. K.: Isothermal cure characterization of fumed silica/epoxy nanocomposites: The glass transition temperature and conversion. Composites Part A: Applied Science and Manufacturing, 41, 473479 (2010). DOI: $10.1016 /$ j.compositesa.2009.12.003

[11] Bharadwaj R. K.: Modeling the barrier properties of polymer-layered silicate nanocomposites. Macromolecules, 34, 9189-9192 (2001). DOI: $\underline{10.1021 / \mathrm{ma} 010780 \mathrm{~b}}$

[12] Yano K., Usuki A., Okada A.: Synthesis and properties of polyimide-clay hybrid films. Journal of Polymer Science Part A: Polymer Chemistry, 35, 22892294 (1997).

DOI: 10.1002/(SICI)1099-0518(199708)35:11<2289:: AID-POLA20>3.0.CO;2-9

[13] Kim J-K., Hu C. G., Woo R. S. C., Sham M-L.: Moisture barrier characteristics of organoclay-epoxy nanocomposites. Composites Science and Technology, 14, 805-813 (2005).

DOI: $10.1016 /$ j.compscitech.2004.10.014

[14] Naya S., Martínez-Vilariño S., Artiaga R.: Efecto de ciclos térmicos en la permeabilidad y propiedades térmicas de compuestos nanoarcilla-epoxi. Dyna, 84, 71-76 (2009).

[15] Huang K-Y., Weng C-J., Lin S-Y., Yu Y-H., Yeh JM.: Preparation and anticorrosive properties of hybrid coatings based on epoxy-silica hybrid materials. Journal of Applied Polymer Science, 112, 1933-1942 (2009). DOI: 10.1002/app.29302

[16] Drzal L. T., Rich M. J., Koenig M. F., Lloyd P. F.: Adhesion of graphite fibers to epoxy matrices: II. The effect of fiber finish. Journal of Adhesion, 16, 133152 (1983). DOI: $10.1080 / 00218468308074911$

[17] Schadler L. S.: Polymer-based and polymer-filled nanocomposites. in 'Nanocomposite Science and Technology' (eds.: Ajayan P. M., Schadler L. S., Braun P. V.) Wiley, Weinheim, 77-135 (2003).

[18] Prime R. B.: Thermosets. in 'Thermal characterization of polymeric materials (second edition)' (ed.: Turi E.) Academic Press, San Diego, 1380-1766 (1997). 
[19] Wetzel B., Haupert F., Zhang M. Q.: Epoxy nanocomposites with high mechanical and tribological performance. Composites Science and Technology, 63, 2055-2067 (2003).

DOI: $10.1016 / \mathrm{S} 0266-3538(03) 00115-5$

[20] Park J. H., Jana S. C.: The relationship between nanoand micro-structures and mechanical properties in PMMA-epoxy-nanoclay composites. Polymer, 44, 2091-2100 (2003).

DOI: $10.1016 / \mathrm{S} 0032-3861(03) 00075-2$

[21] Han J. T., Cho K.: Nanoparticle-induced enhancement in fracture toughness of highly loaded epoxy composites over a wide temperature range. Journal of Materials Science, 41, 4239-4245 (2006).

DOI: $10.1007 / \mathrm{s} 10853-006-6219-2$

[22] Zhang X., Xu W., Xia X., Zhang Z., Yu R.: Toughening of cycloaliphatic epoxy resin by nanosize silicon dioxide. Materials Letters, 60, 3319-3323 (2006). DOI: $10.1016 /$ j.matlet.2006.04.023

[23] Sipaut C. S., Ahmad N., Adnan R., Rahman I. Ab., Bakar M. A., Ismail J., Chee C. K.: Properties and morphology of bulk epoxy composites filled with modified fumed silica-epoxy nanocomposites. Journal of Applied Sciences, 7, 27-34 (2007).

DOI: $10.3923 /$ jas.2007.27.34

[24] Kang S., Hong S. I., Choe C. R., Park M., Rim S., Kim J.: Preparation and characterization of epoxy composites filled with functionalized nanosilica particles obtained via sol-gel process. Polymer, 42, 879-887 (2001). DOI: $10.1016 / \mathrm{S} 0032-3861(00) 00392-X$

[25] Chang K-C., Lin C-Y., Lin H-F., Chiou S-C., Huang W-C., Yeh J-M., Yang J-C.: Thermally and mechanically enhanced epoxy resin-silica hybrid materials containing primary amine-modified silica nanoparticles. Journal of Applied Polymer Science, 108, 1629-1635 (2008).

DOI: 10.1002/app.27559

[26] Tarrio-Saavedra J., López-Beceiro J., Naya S., Artiaga R.: Effect of silica content on thermal stability of fumed silica/epoxy composites. Polymer Degradation and Stability, 93, 2133-2137 (2008).

DOI: $10.1016 /$ j.polymdegradstab.2008.08.006

[27] Llorente M. A., Horta A.: Técnicas de caracterización de polímeros. UNED, Madrid (1991).

[28] Donth E.: The glass transition. Relaxation dynamics in liquids and disordered materials. Springer, Berlin (2001).

[29] Hutchinson J. M., Montserrat S.: The application of modulated differential scanning calorimetry to the glass transition of polymers. I. A single-parameter theoretical model and its predictions. Thermochimica Acta, 286, 263-296 (1996). DOI: $\underline{10.1016 / 0040-6031(96) 02967-X}$
[30] Thomas L. C.: An introduction to the techniques of differential scanning calorimetry (DSC) and modulated DSC. in 'Thermal analysis. Fundamentals and applications to material characterization' (ed.: Artiaga R.) Publicationes de la Universidade da Coruna, Coruna, 9-25 (2005).

[31] Reading M., Hourston D. J.: Modulated temperature differential scanning calorimetry: Theoretical and practical applications in polymer characterisation. Springer, Dordrecht (2006).

[32] Schröter K., Wilde G., Willnecker R., Weiss M., Samwer K., Donth E.: Shear modulus and compliance in the range of the dynamic glass transition for metallic glasses. The European Physical Journal B: Condensed Matter and Complex Systems, 5, 1-5 (1998). DOI: $10.1007 / \mathrm{s} 100510050411$

[33] Artiaga R., García A.: Fundamentals of DMA. in: 'Thermal analysis. Fundamentals and applications to material characterization' (ed.: Artiaga R.) Publicationes de la Publicationes de la Universidade da Coruna, A Coruña, Spain, 183-206 (2005).

[34] Chartoff R. P., Menczel J. D., Dillman S. H.: Dynamic mechanical analysis (DMA). in: 'Thermal analysis of polymers. Fundamentals and applications' (eds.: Menczel J. D., Prime R. B.) Wiley, San Jose, 387-496 (2009).

[35] Menczel J. D., Judovits L., Prime R. B., Bair H. E., Reading M., Swier S.: Differential scanning calorimetry (DSC). in: 'Thermal analysis of polymers. Fundamentals and applications' (eds.: Menczel J. D., Prime R. B.) Wiley, San Jose, 7-239 (2009).

[36] Mohammad A., Simon G. P.: Rubber-clay nanocomposites. in 'Polymer nanocomposites' (eds.: Mai Y-W., Yu Z-Z.) Woodhead Publishing Limited, Abington 297-329 (2006).

[37] Pellín M. P., Regueira L. N., Quintela A. L., Losada P. P., Gándara J. S., Abuín S. P.: Epoxy resins based on trimethylolpropane. II. Kinetic and thermodynamic parameters of cure with $m$-XDA. Journal of Applied Polymer Science, 55, 1507-1516 (1995).

DOI: 10.1002/app.1995.070551102

[38] Pellin M. P., Regueira L. N., Gandara J. S., Losada P. P., Lamela C. P., Abuin S. P.: Epoxy resins based on trimethylolpropane. I. Determination of chemical structres. Journal of Applied Polymer Science, 55, 225-232 (1995). DOI: 10.1002/app.1995.070550205

[39] Quintela A. L., Pellin M. P., Abuin S. P.: Epoxidation reaction of trimethylolpropane with epichlorohydrin: Kinetic study of chlorohydrin formation. Polymer Engineering and Science, 36, 568-573 (1996). DOI: $10.1002 /$ pen. 10443

[40] Webb P. A.: The perseverance of Sedigraph method in particle sizing. Micromeritics Instrument Corporation, January, 1-6 (2004). 
[41] Pena D.: Regresión y diseño de experimentos. Alianza Editorial, Madrid (2002).

[42] Box G. E., Hunter J. S., Hunter W. G.: Estadística para investigadores: Diseno, innovación y descubrimiento. Editorial Reverté, Barcelona (2008).

[43] Maxwell S. E., Delaney H. D.: Designing experiments and analyzing data. A model comparison perspective. Lawrence Erlbaum Associates, New Jersey (2004).

[44] Shapiro S., Wilk M. B.: An analysis of variance test for normality (complete samples). Biometrika, 52, 591-611 (1965).

DOI: 10.1093/biomet/52.3-4.591
[45] Bartlett M. S.: Properties of sufficiency and statistical tests. in 'Proceedings of the Royal Society of London. Series A: Mathematical and Physical Sciences' Vol 160, 268-282 (1937).

[46] Durbin J., Watson G. S.: Testing for serial correlation in least squares regression. I. Biometrika, 37, 409-428 (1950). DOI: $10.1093 /$ biomet/37.3-4.409

[47] Durbin J., Watson G. S.: Testing for serial correlation in least squares regression. II. Biometrika, 38, 159178 (1951).

DOI: $10.1093 /$ biomet/38.1-2.159

[48] Reed K. E.: Dynamic mechanical analysis of fiber reinforced composites. Polymer Composites, 1, 44-49 (1980).

DOI: $\underline{10.1002 / p c .750010109}$ 